J. Lake Sci.(湖泊科学), 2020, 32(2): 417-427

DOI 10. 18307/2020. 0211

(c) 2020 by Journal of Lake Sciences

\title{
三峡建库后东洞庭湖适宜生态水位需求分析”
}

黄宇云, 余明辉**, 陆 晶, 孙昭华, 田浩永

(武汉大学水资源与水电工程科学国家重点实验室,武汉 430072)

\begin{abstract}
摘 要: 三峡水库的修建改变了水库下游的水沙条件, 影响了洞庭湖湖区的生态平衡, 进而引发相关生态问题. 本文以城 陵矶站水位代表东洞庭湖水位, 基于其 1953-2018 年的逐日水位资料, 采用滑动 $t$ 检验法对年平均水位序列进行突变检 验, 发现因强人类活动导致城陵矶水位发生突变的时间为 2004 年, 考虑为三峡蓄水的影响. 借鉴 IHA ( Indicators of Hydrological Alteration,水文变化指标) 及 RVA ( Range of Variability Approach,变化范围法) 方法提出了一种同时考虑年内月平均 水位过程、水位波动范围、高低水位发生情况以及水位涨落情况的适宜生态水位计算指标体系, 能够直观和全面地描述 生态系统健康发展对水位的要求, 包括 $1-12$ 月水位分别为: 17.07 18.34、17.15 18.89、17.65 22.23、20.25 22.15、 $22.85 \sim 24.90 、 24.31 \sim 26.44 、 26.88 \sim 29.16 、 25.79 \sim 28.32 、 25.12 \sim 27.56 、 23.59 \sim 25.88 、 20.65 \sim 22.81 、 18.58 \sim 19.88 \mathrm{~m}$; 年最低水 位: 16.21 17.86 m, 发生时间为第 16 51 天(年积日); 年最高水位: $28.54 \sim 31.48 \mathrm{~m}$, 发生时间为第 $187 \sim 211$ 天(年积日); 高水位平均持续时间为 $32.62 \sim 81.32 \mathrm{~d} /$ 次, 低水位平均持续时间为 $52.13 \sim 107.65 \mathrm{~d} /$ 次; 涨水次数为 $21.9 \sim 26.45$ 次, 涨水 速率为 $0.17 \sim 0.21 \mathrm{~m} / \mathrm{d}$; 落水次数为 $23.17 \sim 27.6$ 次, 落水速率为 $0.12 \sim 0.14 \mathrm{~m} / \mathrm{d}$. 基于上述结果分析三峡建库后城陵矶水 位发现, 其在 $1 、 2$ 月月平均水位分别较适宜生态水位需求高 $0.83 、 0.27 \mathrm{~m} ; 10$ 月月平均水位较需求低 $0.83 \mathrm{~m}$; 年最低水位 高出需求 $0.39 \mathrm{~m}$, 发生时间先于需求 6 天; 涨水次数高于國值要求 4 次, 涨水速率低于國值要求 $0.01 \mathrm{~m} / \mathrm{d}$; 落水次数高于 阈值要求 2 次. 研究成果可为三峡及上游梯级水库群联合调度提供依据.
\end{abstract}

关键词: 三峡工程; 东洞庭湖;城陵矶;适宜生态水位; 突变检验; IHA 法

\section{Suitable ecological water level of the East Lake Dongting after the Three Gorges Project operation *}

HUANG Yuyun, YU Minghui ${ }^{* *}$, LU Jing, SUN Zhaohua \& TIAN Haoyong

( State Key Laboratory of Water Resources and Hydropower Engineering Science, Wuhan University, Wuhan 430072, P.R.China)

Abstract: The operation of the Three Gorges Dam has changed the flow and sediment conditions in the lower reaches of the reservoir, and it affected the ecological balance of the Lake Dongting and resulted in corresponding ecological problems. $T$-test was adopted for testing the consistency of the annual average water level based on the daily water level data of 1953-2018 at Chenglingji Station which is taken as the water level of the East Lake Dongting. The results show that the year of 2004 is an abrupt change point, indicating that the operation of Three Gorges Dam has resulted in the dramatic variation of water level at Chenglingji Station. Drawing on the IHA (Indicators of Hydrological Alteration) and RVA ( Range of Variability Approach), an index system for calculating suitable ecological water level was presented in consideration of the range of monthly mean water level, the fluctuation range of annual water level, frequency and duration of high and low water level, and rate and frequency of water level condition changes. This index system can represent the requirements of the original ecological system intuitively and comprehensively. Using this index system, the suitable ecological water level of East Lake Dongting before the operation of the Three Gorges Dam was calculated for the following variables: 1) the range of monthly mean water level (from January to December) : 17.07-18.34 m, 17.15-18.89 m, $17.65-22.23 \mathrm{~m}, 20.25-22.15 \mathrm{~m}, 22.85-24.90 \mathrm{~m}, 24.31-26.44 \mathrm{~m}, 26.88-29.16 \mathrm{~m}, 25.79-28.32 \mathrm{~m}, 25.12-27.56 \mathrm{~m}, 23.59-$ $25.88 \mathrm{~m}, 20.65-22.81 \mathrm{~m}, 18.58-19.88 \mathrm{~m}$, respectively ; 2) annual acminimum water level: $16.21-17.86 \mathrm{~m}$, occurring from day 16 to day 51 (annual accumulative day) ; 3) annual maximum water level: 28.54-31.48 m, occurring from day 187 to day 211

* 2019-05-22 收稿; 2019-09-28 收修改稿.

国家重点研发计划项目(2016YFC0402303) 和国家自然科学基金项目( 11972265) 联合资助.

** 通信作者; E-mail:mhyu@ whu.edu.cn. 
(annual accumulated day); 4) the high water level lasts 32.62-81.32 days at one time, the low water level lasts 52.13-107.65 days at one time, water level rises 21.9-26.45 times, the rate of water rising is $0.17-0.21 \mathrm{~m} / \mathrm{d}$, water level falls $23.17-27.6$ times, the rate of water falling is $0.12-0.14 \mathrm{~m} / \mathrm{d}$. The results indicate that the monthly mean water level in January and February is $0.83 \mathrm{~m}$ and $0.27 \mathrm{~m}$ lower than the demand for suitable ecological water level, the monthly average water level in October is $0.83 \mathrm{~m}$ higher than the demand, the annual minimum water level is $0.39 \mathrm{~m}$ higher than the demand, occurring 6 days earlier than demand. The research results can provide a basis for the joint operation of Three Gorges and upstream cascade reservoirs.

Keywords: Three Gorges Project; East Lake Dongting; Chenglingji Station; suitable ecological water level; mutation test; IHA

长江是我国最大的河流,具有重要的人文、社会经济功能 ${ }^{[1]}$. 洞庭湖为长江中游荆江河段重要的通江湖 泊,是我国第二大淡水湖,具有调节河川径流、改善生态环境、供水灌溉等功能 ${ }^{[2]}$. 三峡工程蓄水后洞庭湖面 积及水位等水文特征发生了明显变化,如: 胡金金等 ${ }^{[3]}$ 基于 MODIS 数据分析了洞庭湖 2000-2014 年湖泊面 积变化发现研究期间湖泊面积明显萎缩,调洪蓄水功能减弱. 孟熊等 ${ }^{[4]}$ 分析发现三峡建库后洞庭湖各站常 水位、相应站枯水位较建库前有明显降低, 城陵矶 (七里山) 水文站 (简称城陵矶站) 枯水位则有所抬高. 这 些水文特征的变化改变了洞庭湖的生态环境, 影响其生态结构和生物多样性, 同时影响其生态系统良性健 康的发展. 如: 张光贵等 ${ }^{[5]}$ 研究发现三峡蓄水后洞庭湖内梅罗污染指数 $I_{P}$ 值和总磷、总氮浓度均有不同程度 的升高; 王琦等 ${ }^{[6]}$ 也发现三峡工程运行后, 洞庭湖水文水动力环境条件的变化整体上对水质产生了不利影 响, 促进了洞庭湖的富营养化. 此外, 建库等人类活动会造成工程下游水位过程坦化, 直接表现在年水位过 程中最高水位的降低和最低水位的升高, 水位波动范围减小. 水位的周期波动形成了大面积的草本湿地群 落, 维持了湿地丰富的物种多样性 ${ }^{[7]}$, 但是由于洞庭湖水位变化, 大片的湖底裸露成泥滩, 湿地面积减小, 水 禽栖息地和受食地的面积有所减小, 给洞庭湖湿地的物种多样性以及当地的冬候鸟造成了较大的威胁 ${ }^{[8]}$. 且有研究表明, 湖泊现存的植被类型是对水位长期变动的适应, 不正常的水位变异会产生负面影响, 如冬季 水位过高会对越冬水鸟产生负面影响,早春水位过高会导致沉水植被无法正常萌芽和生长,而最高水位的 降低会导致湖泊面积萎缩, 且水位波动的减小, 无法保证原有的湖泊与湿地营养盐的交换, 降低湖泊湿地生 态系统的物种多样性, 破坏其生态系统平衡 ${ }^{[9-11]}$. 因此研究维持洞庭湖生态系统健康发展的条件是三峡工程 运行后亟待解决的问题之一.

随着人类社会的快速发展, 1990s 淡水资源的储存不足和管理不当造成了广泛的生态问题和人类淡水 利用危机, 而没有相关措施保证生态需水, 生态需水量的研究应运而生, 1998 年 Gleick 提出基本生态需水量 (Basic Water Requirement) 的概念, 即保证物种多样性和生态完整性的基本需水量 ${ }^{[12]}$. 不同学者提出了众多 相关概念, 如最小河流需水量 ( minimum instream flow requirements)、环境需水量 (environmental instream flow requirements) 等 ${ }^{[13]}$; 在国内相关概念有生态流量、最小生态需水量等 ${ }^{[14-15]}$. 因其研究起步早, 研究成果丰富, 据 2003 年统计, 有记载的生态流量的计算方式多达 207 种 ${ }^{[16]}$, 主要类别: 水文学法 ( Tennant 法、Texas 法、 NGPRP 法、IHA 法 $)^{[17-20]}$ 、水力学法 (湿周法、R2-CROSS 法) ${ }^{[21]}$ 、栖息地法(有效宽度法、IFIM 法 $)^{[18]}$ 及整体 法 (BBM 法、澳大利亚 ELOHA 法) ${ }^{[22-23]}$. 水位是衡量河湖水情的一个重要指标. 生态水位开始研究的时间与 生态需水量相近 ${ }^{[24]}$, 湖泊生态需水量研究主要集中于生态水位的研究, 不同的学者根据不同的研究目的给 出了生态水位的定义 ${ }^{[25-26]}$, 大多集中在最低生态水位的界定和研究. 目前最低生态水位的计算方法主要有:

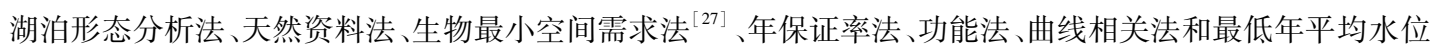
法 ${ }^{[14]}$. 这些方法计算结果均为单一值 ${ }^{[28-29]}$, 没有考虑不同时间生态系统对水位要求的不同, 且上述研究皆 集中于最低生态水位, 但最低生态水位是维持生态系统基本功能不严重退化的水位, 是短时间保持的水位, 如果长时间保持这种水位,生态系统依然会崩溃 ${ }^{[30]}$. 为此, 有学者从湖泊天然水位情势中提取出高低水位 历时、发生时间和变化率等水位指标多角度地表征生态水位过程要求,并应用到鄱阳湖生态水位计算中 ${ }^{[31]}$. 但这类方法忽略了因水库建设导致的下游水位过程坦化, 因此本文研究能够维持生态系统结构稳定、健康 发展的适宜生态水位过程, 同时考虑年内逐月水位过程、水位波动情况.

本文借鉴 IHA 指标体系构建东洞庭湖适宜生态水位计算指标体系,包括年内 12 个月月平均水位、最高 水位及其出现时间、最低水位及其出现时间、高低水位发生次数、高低水位平均持续时间、涨落水次数、涨落 水速率等共 24 个指标. 以城陵矶站水位作为东洞庭湖代表水位, 采用滑动 $t$ 检验法对城陵矶站年均水位进 
行突变检验, 将突变前的水位作为维持东洞庭湖生态系统健康发展的水位过程 ${ }^{[22-34]}$, 基于此利用所提出的 指标体系计算东洞庭湖适宜生态水位过程.

\section{1 研究区域与数据资料}

本文研究范围为东洞庭湖湖区 (图 1), 洞庭湖西部和南部有湘、资、沅、澧“四水” 入湖并承接由松滋、太 平、藕池“三口” 分泄的长江干流的水流, 经由城陵矶汇人长江干流, 分为东洞庭湖、南洞庭湖和西洞庭湖. 本 文采用城陵矶站 1953-2018 年逐日水位进行适宜生态水位研究, 水位序列来源于水文年鉴等资料, 文中各 水文站水位均已统一为黄海高程.

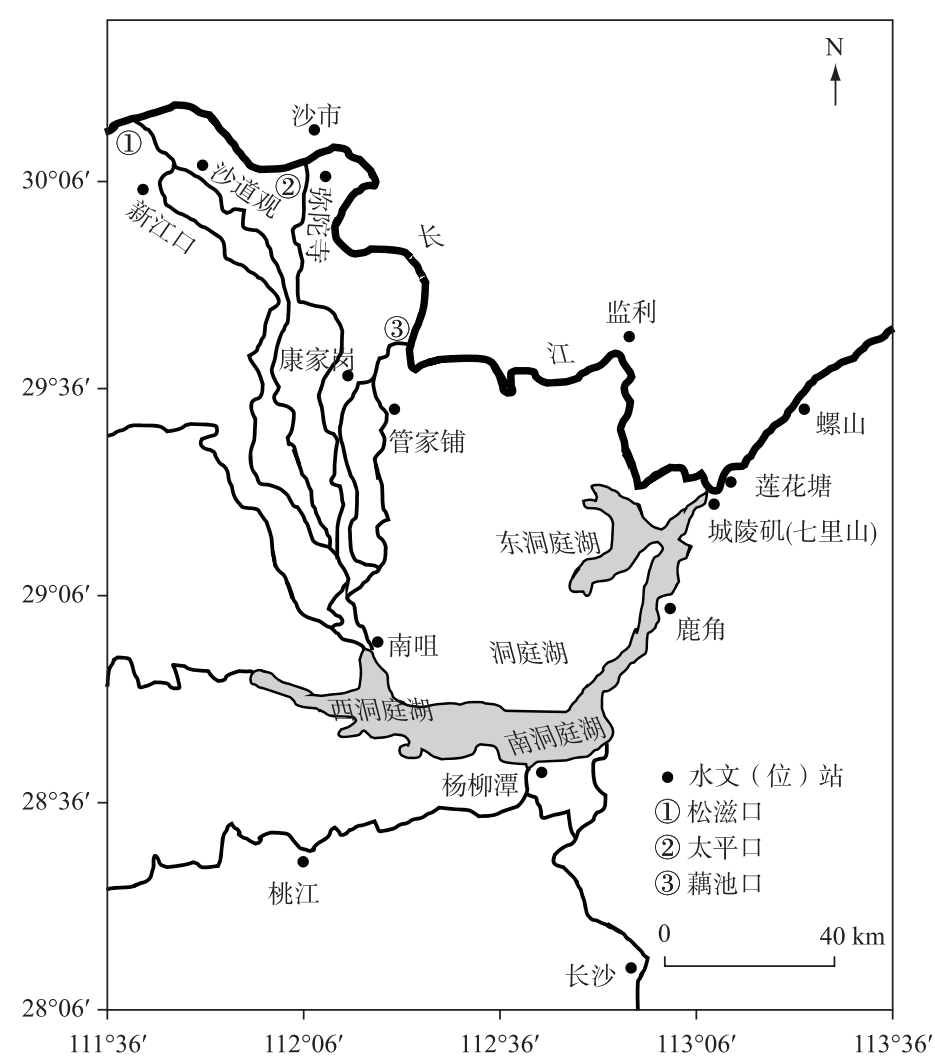

图 1 研究区域地理位置

Fig.1 Geographical location of research area

\section{2 研究方法}

\section{1 滑动 $t$ 检验法}

本文采用滑动 $t$ 检验法对城陵矶年均水位序列进行突变点检测. 假定水位序列为 $x=\left\{x_{1}, x_{2}, \cdots, x_{n}\right\}$, 设 突变点为 $m$. 假设突变点前后两个序列总体的分布函数各为 $\mathrm{F}_{1}(x)$ 和 $\mathrm{F}_{2}(x)$. 从总体 $\mathrm{F}_{1}(x)$ 和 $\mathrm{F}_{2}(x)$ 中分别 抽取容量为 $n_{1}$ 和 $n_{2}$ 的 2 个样本, 构造 $t$ 统计量:

$$
\begin{gathered}
t=\frac{\overline{x_{1}}+\overline{x_{2}}}{s_{\omega} \sqrt{\frac{1}{n_{1}}+\frac{1}{n_{2}}}} \\
s_{\omega}^{2}=\frac{\left(n_{1}-1\right) s_{1}^{2}+\left(n_{2}-1\right) s_{2}^{2}}{n_{1}+n_{2}-2}
\end{gathered}
$$


式中, $\overline{x_{i}}$ 和 $s_{i}$ 分别为样本均值和样本标准差; $s_{\omega}$ 为 $n_{1}$ 和 $n_{2}$ 合样本的标准差. 在置信度水平 $\alpha$ 的条件下, 当 $|t|>t_{\alpha / 2}$ 时, 该序列存在明显差异; 当 $|t|<t_{\alpha / 2}$ 时, 该序列不存在明显差异.

\section{2 适宜生态水位指标体系}

IHA (Indicators of Hydrological Alteration) 方法是 Richter 等 ${ }^{[20]}$ 于 1996 年提出基于 20 年以上的水文数据 系统地计算河流生态流量的指标体系, 共 5 组 32 个指标, 1998 年增补至 33 个指标 ${ }^{[35]}$, 该方法不仅考虑了维 持河流生态环境的最低流量, 同时要求河流保留天然洪水特征来维持河流河滨生态系统健康. 由于 IHA 法 中每个指标是定值, 在使用时只能计算河流受到人类活动扰动后各个指标相对天然情况下的偏离程度, 无 法判断受扰动后的河流生态系统是否健康, 因此 Richter 等在 1997 年提出了 RVA(Range of Variability Approach) 法计算 IHA 法中指标可接受的阈值 ${ }^{[36]}$. 大部分的研究中选取 IHA 各指标发生频率 $25 \%$ 和 $75 \%$ 的值 作为该指标参数 RVA 阈值 ${ }^{[15,37-39]}$. 本文借鉴了 IHA 指标体系以及 RVA 阈值法对城陵矶适宜生态水位进行 计算研究. 为了在保证月均水位过程的同时也能够保证正常的年内水位波动情况, 本文采用年内 12 个月月 平均水位、最高水位及其出现时间、最低水位及其出现时间、高低水位发生次数、高低水位平均持续时间、涨 落水次数、涨落水速率等共 24 个指标作为适宜生态水位计算指标体系, 每个指标相应的阈值为适宜生态水 位需求 ${ }^{[10,20]}$, 具体指标说明如下:

2.2.1 年内月平均水位指标 选用水位序列每个月多年月平均水位作为城陵矶每个月的适宜生态水位指标 $\left(A Z_{i}(i=1 \sim 12), \mathrm{m}\right)$, 并将当月月均水位发生频率为 $25 \%$ 和 $75 \%$ 的值作为当月适宜生态水位阈值要求, 用来 满足各个时期不同生物对水位的需要.

2.2.2 极端水位指标 选用年内最高水位 $\left(Z_{\text {max }}, \mathrm{m}\right)$ 、最低水位 $\left(Z_{\text {min }}, \mathrm{m}\right)$ 和相应的发生时间 $\left(T Z_{\text {max }}, T Z_{\text {min }}\right.$, 按年 积日计) 作为极端水位指标; 并将每个指标发生频率为 $25 \%$ 和 $75 \%$ 的值作为其阈值要求, 极端水位可保证湖 泊面积、湿地面积、地下水位等要素, 极端水位出现时间是为了满足生态系统中某些生物的生命周期需要.

2.2 .3 高低水位发生次数及持续时间 选定日水位序列中 $25 \%$ 为高水位, $75 \%$ 为低水位, 结合涂峰等 ${ }^{[31]}$ 的研 究, 认为高于高水位时间持续 7 天及以上为高水位事件, 同理低于低水位时间持续 7 天及以上为低水位事 件,年内高/低水位总持续时间除以高/低水位事件次数为高/低水位平均持续时间, 统计建库前后每年高/ 低水位发生次数 $\left(N_{\mathrm{h}} 、 N_{1}\right.$, 次) 及年内高/低水位平均持续时间 $\left(T_{\mathrm{h}} 、 T_{1}\right.$, $\mathrm{d} /$ 次), 以相应指标发生频率 $25 \%$ 和 $75 \%$ 处的值作为阈值, 高低水位发生次数及持续时间与某些物种特定的生长阶段有关.

2.2.4 张落水次数及速率 日间水位上涨 (落) 数为涨 (落) 水率 $\left(V_{\mathrm{r}} 、 V_{\mathrm{d}}, \mathrm{m} / \mathrm{d}\right)$, 连续日间水位上涨 (落) 为一 次涨 (落) 水 $\left(N_{\mathrm{r}} 、 N_{\mathrm{d}}\right.$, 次), 统计建库前后每年涨落次数以及年均涨落水速率, 以相应指标发生频率 $25 \%$ 和 $75 \%$ 处的值作为阈值, 水位的涨落次数及速率与某些搁浅在水边的生物或植物根系与水源保持接触能力有 关, 同时保证湖泊的自净能力.

\section{3 结果分析}

\section{1 水位突变点}

采用滑动 $t$ 检验法对城陵矶年均水位序列进行突变点检测, 0.05 显著性水平下最可能的突变点为 1980 年和 2004 年. 水位序列是否具有一致性决定于流域的气候条件和下垫面条件是否稳定, 从长江上的历史事 件来看, 两次突变可能是流域内气候条件变化加上葛洲坝截流、三峡水库蓄水所致. Yuan 等 ${ }^{[00]}$ 研究显示, 1980 年前后洞庭湖水文情势发生变化气候影响占主导地位, 而 2003 年前后水文情势发生变化人类活动的 影响占主导地位, 同时根据廖文婷等 ${ }^{[41]}$ 的研究, 相对于三峡建库而言葛洲坝截流导致的其下游水流条件变 化贡献率很小, 这主要是由于葛洲坝水利枢纽属于低水头径流式水电站, 径流调节能力较小, 因此长江中游 城陵矶水位因人类活动导致的突变点最可能是 2004 年, 三峡蓄水后第一年.

\section{2 三峡建库前后城陵矶水位特征分析}

3.2.1 日水位过程分析 建库前城陵矶站水位年内变化为典型的单峰分布 (图 2a), 具有明显的高、低水位变 化, 整体而言, 年初到 7 月水位逐渐上升到最大值随后下降, 多年日平均水位变化范围为 $17.66 \sim 28.57 \mathrm{~m}$, 多 年最高水位变化范围为 $20.47 \sim 33.89 \mathrm{~m}$, 多年最低水位变化范围为 $15.25 \sim 24.96 \mathrm{~m}$, 同一天多年最高水位与 多年最低水位差值变化范围为 4.8 13.16 m; 建库后该站水位年内分布图形态与建库前相同 (图 $2 \mathrm{~b}$ ), 但建 
库后汛期多年最高水位较建库前有明显降低,年初枯水期多年最低水位较建库前有明显上升,年内水位过 程曲线明显坦化, 且汛末三峡蓄水期多年最低水位较建库前有所降低. 建库后多年日平均水位变化范围为 18.9 28.42 m, 多年最高水位变化范围为 $19.69 \sim 32.57 \mathrm{~m}$, 多年最低水位变化范围为 $17.28 \sim 26.37 \mathrm{~m}$. 同一天 多年最高水位与多年最低水位差值变化范围为 $1.85 \sim 8.91 \mathrm{~m}$,较建库前有明显减小.

(a) 建库前(1953-2003年)

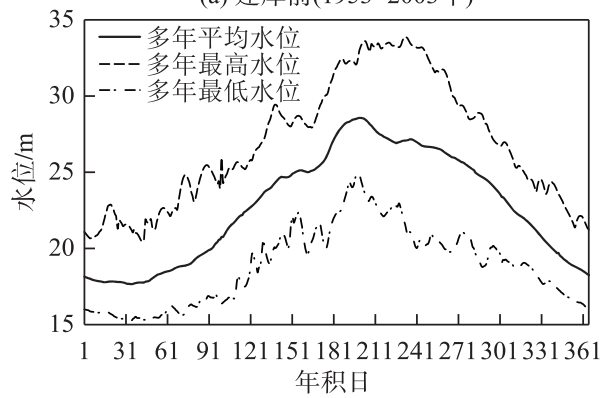

(b) 建库后(2004-2018年)

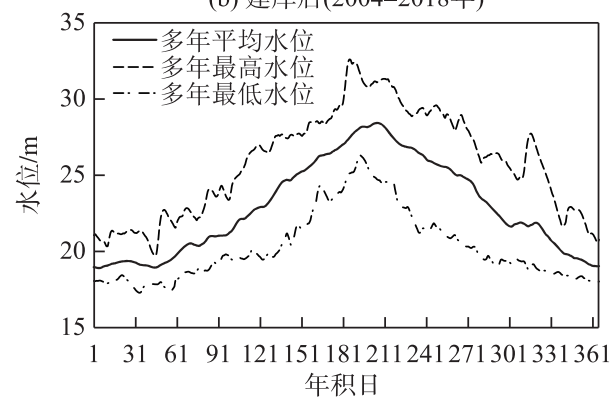

图 2 三峡建库前、后城陵矶站水位日变化

Fig.2 Diurnal variation of water level in Chenglingji Station pre and post the construction of TGD

3.2.2 月平均水位过程分析 根据计算结果 (表 1), 三峡建库前月平均水位变化范围为 $17.86 \sim 28.17 \mathrm{~m}$, 建库 表 1 城陵矶站适宜生态水位计算成果

Tab.1 Calculation results of suitable ecological water level of Chenglingji Station

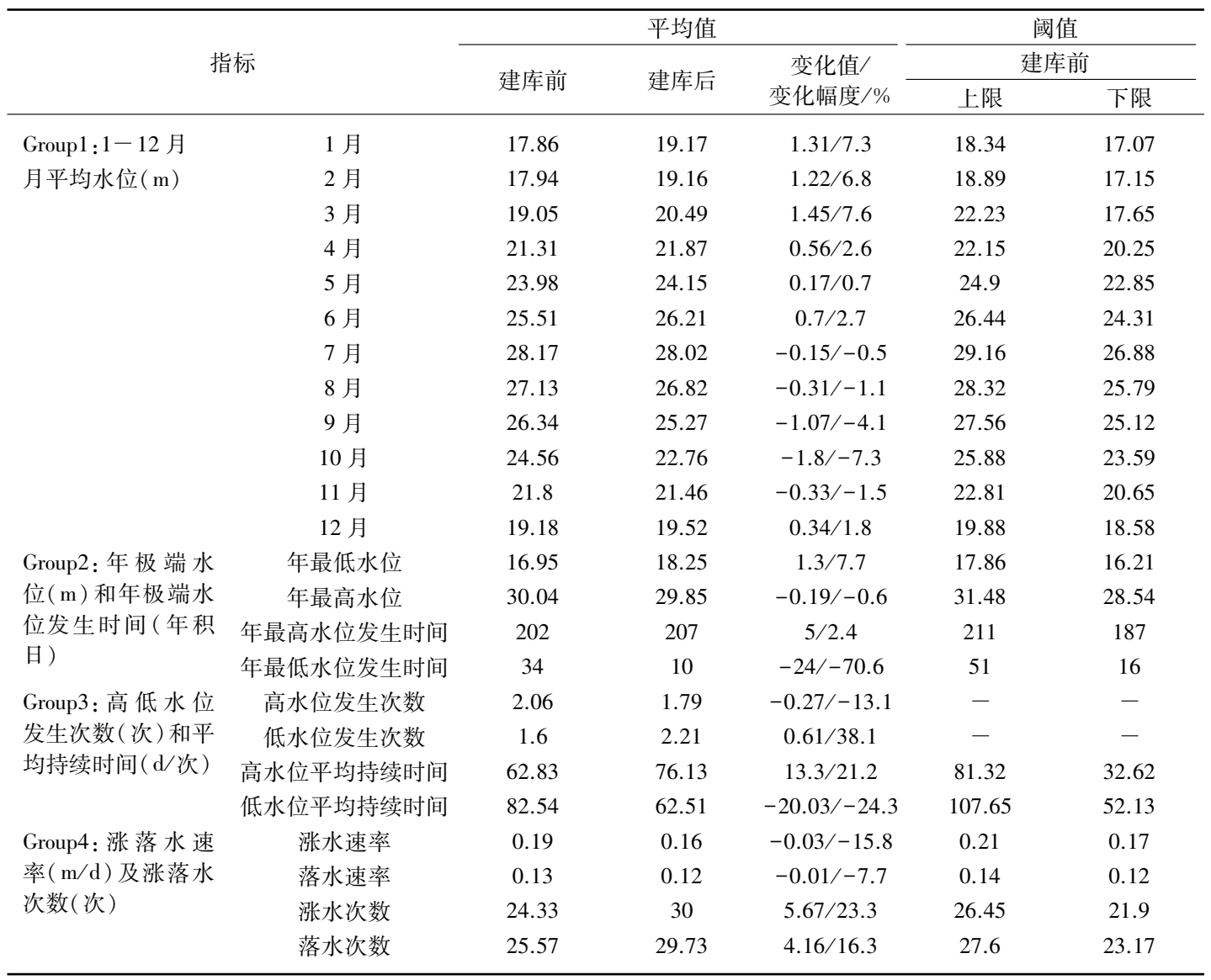


后月平均水位变化范围为 19.16 28.02 m, 年内最高与最低月平均水位差变小. $1-6$ 月, 月平均水位较建库 前升高, 变化值为 $0.17 \sim 1.45 \mathrm{~m}$, 最大变化率为 $7.6 \% ; 7-11$ 月, 月平均水位较建库前降低, 变化值为 $-0.15 \sim$ $-1.80 \mathrm{~m}$, 最大变化率为 $-7.3 \%$, 而 12 月份水位平均升高了 $0.34 \mathrm{~m}$, 变化率为 $1.8 \%$, 由于三峡水库的调度调 节,东洞庭湖枯水期水位上升, 汛期水位降低.

3.2 .3 年最高、最低水位分析 从建库前后年最低水位大小来看, 建库前年最低水位为 $15.25 \sim 18.83 \mathrm{~m}$, 多年 平均最低水位为 $16.95 \mathrm{~m}$; 建库后最低水位为 $17.92 \sim 18.63 \mathrm{~m}$, 多年平均最低水位为 $18.25 \mathrm{~m}$; 可以看出建库 后年最低水位整体比建库前有了明显的升高, 且变化范围减小 (图 3a). 从建库前后最高水位大小来看, 建 库前年最高水位为 $26.23 \sim 33.89 \mathrm{~m}$, 多年平均最高水位为 $30.04 \mathrm{~m}$; 建库后最高水位为 $27.38 \sim 32.57 \mathrm{~m}$, 多年 平均最低水位为 $29.85 \mathrm{~m}$, 建库后年最高水位相对于建库前略有降低( 图 $3 \mathrm{~b}$ ).
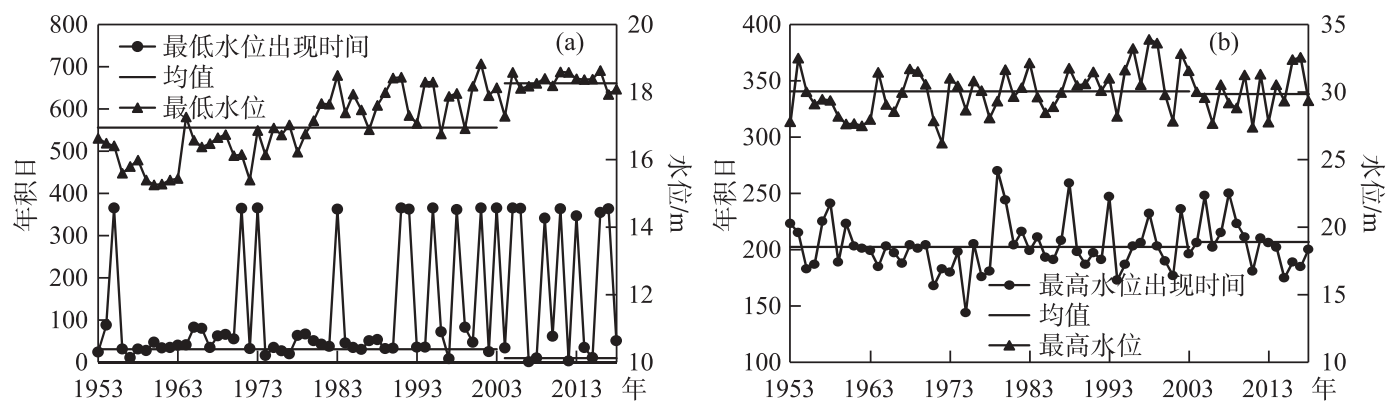

图 3 三峡建库前、后城陵矶站年最高水位、最低水位及其相应发生时间

Fig.3 Timing and value of annual maximum and minimum water level of Chenglingji Station pre and post the construction of TGD

3.2 .4 高低水位发生次数及历时 将 1953-2003 和 2004-2018 年日水位序列分别排序, 取 25\% 和 75\% 频率 下的水位作为高、低水位, 建库前高水位为 $25.45 \mathrm{~m}$, 低水位为 $19.94 \mathrm{~m}$, 建库后高水位为 $24.98 \mathrm{~m}$, 低水位为 $20.44 \mathrm{~m}$. 分别统计建库前后每年高低水位发生次数及平均持续时间 (表 1), 从高低水位发生次数来看, 建库 前后高低水位发生次数没有太大的变化,均为 2 次左右. 从建库前后高低水位持续时间来看 (图 4), 建库前 多年平均高水位持续时间为 $62.83 \mathrm{~d} /$ 次, 建库后多年平均高水位持续时间为 $76.13 \mathrm{~d} /$ 次, 增加约 $13 \mathrm{~d} /$ 次, 变 化幅度为 $21.2 \%$; 建库前多年平均低水位持续时间为 $82.54 \mathrm{~d} /$ 次, 建库后多年平均低水位持续时间为 62.51 $\mathrm{d} /$ 次, 减少约 $20 \mathrm{~d} /$ 次, 变化幅度为 $24.3 \%$.
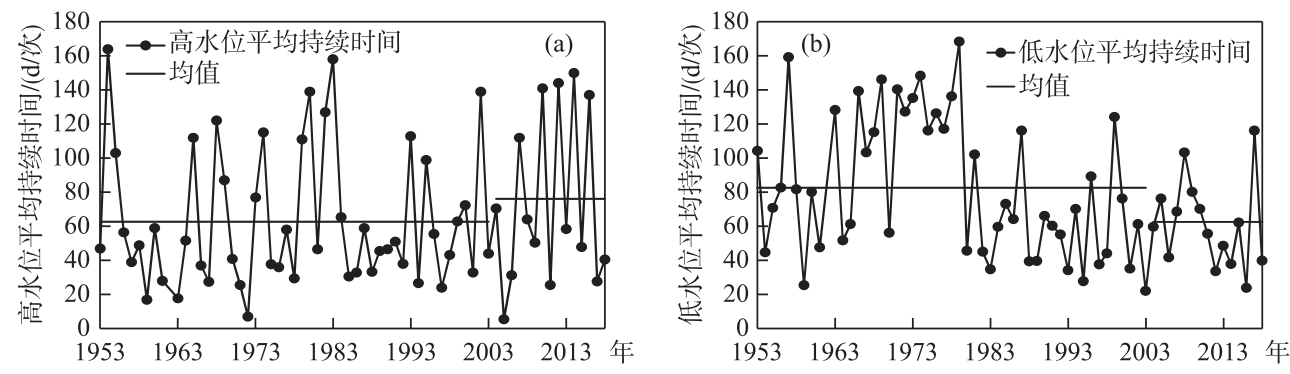

图 4 三峡建库前、后城陵矶站高、低水位持续时间

Fig.4 Duration of high (low) water level of Chenglingji Station pre and post the construction of TGD

3.2 .5 涨落水速率及涨落水次数 从建库前后年内涨落水次数来看 (图 5 ), 建库前多年平均涨水次数为 24.33 次, 建库后多年平均涨水次数为 30 次, 增加约 6 次, 变化幅度为 $23.3 \%$; 建库前多年平均落水次数为 25.57 次, 建库后多年平均落水次数为 29.73 次, 增加约 4 次, 变化幅度为 $16.3 \%$. 从建库前后年内平均涨落 水速率来看 (图 6), 建库前多年平均涨水速率为 $0.19 \mathrm{~m} / \mathrm{d}$, 建库后多年平均涨水速率为 $0.16 \mathrm{~m} / \mathrm{d}$, 降低 0.03 
$\mathrm{m} / \mathrm{d}$, 变化幅度为 $15.8 \%$; 建库前多年平均落水速率为 $0.13 \mathrm{~m} / \mathrm{d}$, 建库后多年平均落水速率为 $0.12 \mathrm{~m} / \mathrm{d}$, 减少 $0.01 \mathrm{~m} / \mathrm{d}$, 变化幅度为 $7.7 \%$. 由此可以看出, 三峡建库后水位涨落更加频繁, 但是涨落水的速率都有所降低, 其原因可能是三峡建库后为了发电频繁调度, 改变了天然径流过程, 导致下游地区水位波动次数增加, 涨落 水速率减小.
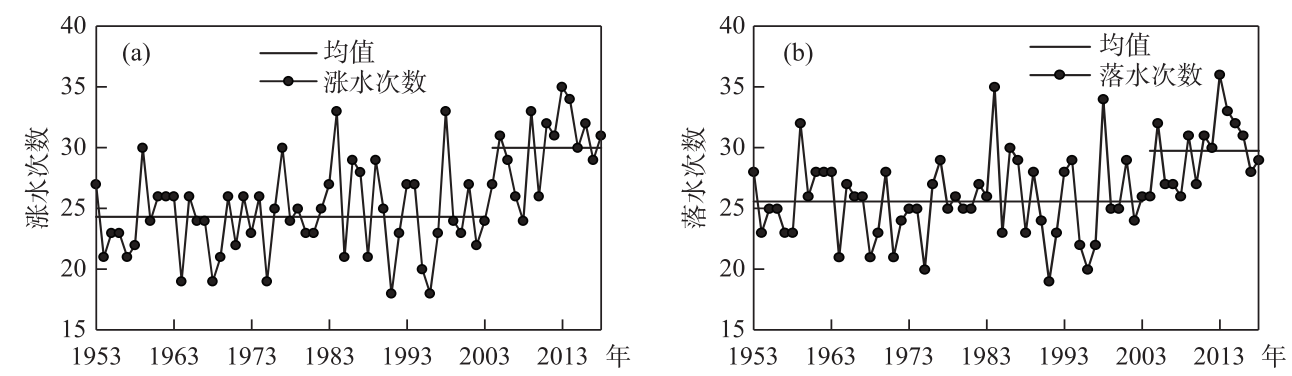

图 5 三峡建库前、后城陵矶站涨、落水次数

Fig.5 Frequency of water level condition changes of Chenglingji Station pre and post the construction of TGD
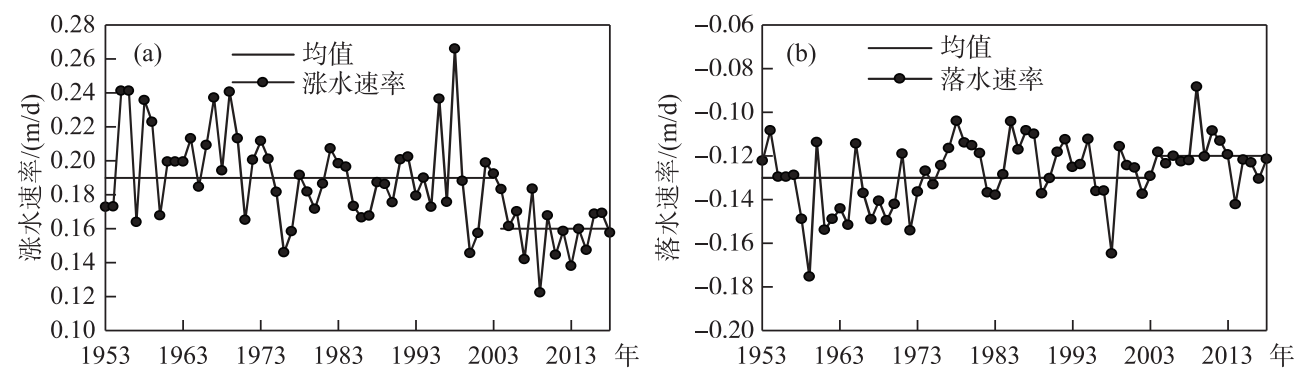

图 6 三峡建库前、后城陵矶站涨、落水速率

Fig.6 Means of all positive (negative) difference between consecutive daily means of water level of Chenglingji Station pre and post the construction of TGD

\section{3 城陵矶适宜生态水位分析}

由于检测出水文突变点为 2004 年, 可认为东洞庭湖区生态系统已经适应了突变前 1953-2003 年的水 位过程,因此本文利用 1953-2003 年的实测水位资料计算城陵矶的适宜生态水位. 基于城陵矶 1953-2003 年逐日水位资料,采用上文 (2.2 节) 所提出的适宜生态水位计算指标体系计算城陵矶适宜生态水位 (表 1), 由于高低水位发生次数建库前后平均发生次数均为 2 次, 因而在适宜生态水位过程的需求中不考虑高低水 位发生次数, 适宜生态水位过程需同时满足以下内容: $1-12$ 月月平均水位: $17.07 \sim 18.34 、 17.15 \sim 18.89$ 、 $17.65 \sim 22.23 、 20.25 \sim 22.15 、 22.85 \sim 24.9 、 24.31 \sim 26.44 、 26.88 \sim 29.16 、 25.79 \sim 28.32 、 25.12 \sim 27.56 、 23.59 \sim$ $25.88 、 20.65 \sim 22.81 、 18.58 \sim 19.88 \mathrm{~m}$; 年最低水位及其发生时间: $16.21 \sim 17.86 \mathrm{~m}$, 发生时间第 $16 \sim 51$ 天 (年积 日); 年最高水位及其发生时间: 28.54 31.48 m, 发生时间第 187 211 天 (年积日); 高水位平均持续时间 $32.62 \sim 81.32 \mathrm{~d} /$ 次, 低水位平均持续时间 $52.13 \sim 107.65 \mathrm{~d} /$ 次; 涨水次数 $21.9 \sim 26.45$ 次, 涨水速率 $0.17 \sim 0.21$ $\mathrm{m} / \mathrm{d}$; 落水次数 $23.17 \sim 27.6$ 次, 落水速率 $0.12 \sim 0.14 \mathrm{~m} / \mathrm{d}$.

三峡建库后城陵矶适宜生态水位满足情况分析, 基于城陵矶适宜生态水位计算结果, 分析城陵矶20042018 年水位是否满足其需求 (表 1), 三峡建库后大部分时间能够满足需求, 但消落期 1 月份多年月平均水 位 $(19.17 \mathrm{~m})$ 较适宜生态水位需求 $(17.07 \sim 18.34 \mathrm{~m})$ 最大值高 $0.83 \mathrm{~m}, 2$ 月份多年平均水位 $(19.16 \mathrm{~m})$ 较适宜 生态水位需求 $(17.15 \sim 18.89 \mathrm{~m})$ 高 $0.27 \mathrm{~m}$; 蓄水期 10 月月平均水位为 $22.76 \mathrm{~m}$, 较适宜生态水位需求 $(23.59 \sim 25.88 \mathrm{~m})$ 最小值低了 $0.83 \mathrm{~m}$, 不能满足需求. 建库后多年平均最低水位为 $18.25 \mathrm{~m}$, 高出适宜生态水 位需求 $(16.21 \sim 17.86 \mathrm{~m}$ ) $0.39 \mathrm{~m}$, 发生在第 10 天 (为第 $16 \sim 51$ 天), 先于需求 6 天; 建库后多年平均最低水位 
为 $29.85 \mathrm{~m}$, 发生在第 207 天, 均满足需求 (28.54 31.48 m, 第 $187 \sim 211$ 天). 建库后高水位平均持续时间 $76.13 \mathrm{~d} /$ 次, 满足阈值要求; 建库后低水位平均持续时间 $62.51 \mathrm{~d} /$ 次, 满足阈值要求; 建库后涨水次数 30 次, 高于國值要求 4 次, 建库后涨水速率 $0.16 \mathrm{~m} / \mathrm{d}$, 低于國值要求 $0.01 \mathrm{~m} / \mathrm{d}$; 建库后落水次数 29.73 次, 高于國值 要求 2 次,建库后落水速率 $0.12 \mathrm{~m} / \mathrm{d}$, 等于國值下限.

\section{4 讨论}

将本文计算所得生态水位与采用同站水位数据进行生态水位的研究成果进行对比分析, 汇总如表 2 所 示 (数据已换算至黄海高程). 程俊翔等 ${ }^{[29]}$ 、杨毓金金等 ${ }^{[42]}$ 分别采用天然水位资料法、年保证率法、最低年平 均水位法、生态水位法、湖泊形态分析法及生物最小空间需求法等方法计算得到东洞庭湖最低生态水位, 上 述研究中天然水位资料法、年保证率法、生态水位法是基于年均水位进行计算, 是对湖泊年均最低水位的约 束,而本文旨在算出适宜生态水位过程, 且文中适宜生态水位过程是逐月平均水位和极端水位发生时间、高 低水位发生次数以及水位涨落情况共同约束的结果, 无法直接对月水位过程进行平均得出年均水位与已有 成果进行比较; 最低年生态水位法是多年平均最低水位乘以权重得到最低生态水位, 其中权重由专家打分, 无法获知其打分依据; 生物最小空间需求法基于日均水位, 从不同的生态需求出发得到最低生态水位,而本 文是用指标从生态系统整体出发进行约束得到适宜生态水位过程;湖泊形态分析法基于湖泊形态计算生态 水位,在湖泊枯水期低水位附近湖泊面积随水位变化最大处对应的水位为最低生态水位, 即在该水位下, 湖 泊水位每降低一个单位, 湖泊水面面积的减少量将显著增加, 相应的湖泊功能的减少量也将显著增加 ${ }^{[27]}$, 这 个方法主要是从湖泊地形的角度, 保证湖泊面积来保证生态系统不崩溃, 与本文方法的角度不同、目的不同. Zhang 等 ${ }^{[43]}$ 采用元余分析法和响应面分析法以洞庭湖水鸟丰富度为目标计算了最低保护水位,低于本文枯 期水位要求的下限, 因而满足本文的水位过程要求, 就可满足洞庭湖水鸟枯期对水位的需求. 梁婕等 ${ }^{[33]}$ 拟 合 1952-1980 年各月月平均水位的最适合的概率分布函数, 认为概率最高的月平均水位作为当月的生态水 位, 由此得出东洞庭湖逐月生态水位, 该成果 3 月份生态水位低于本文 3 月份水位要求下限 $3 \mathrm{~cm}$, 其他月份 均在本文第一类指标月均水位范围内.

表 2 东洞庭湖湖区生态水位研究成果对比

Tab.2 Comparison of research results on ecological water level at East Lake Dongting

\begin{tabular}{|c|c|c|c|c|}
\hline 成果来源 & 研究数据站点 & $\begin{array}{l}\text { 研究水位 } \\
\text { 时间序列 }\end{array}$ & 研究方法 & 计算成果 \\
\hline 程俊翔等 ${ }^{[27]}$ & 城陵矶站 & 1955-2011 年 & $\begin{array}{l}\text { 最低年平均水位法、年保证率设定法、 } \\
\text { 湖泊形态分析法、生态水位法 }\end{array}$ & 最低生态水位 23.39 m \\
\hline 杨毓金金等 ${ }^{[41]}$ & $\begin{array}{l}\text { 城陵矶站、 } \\
\text { 鹿角站 }\end{array}$ & $1953-2013$ 年 & $\begin{array}{l}\text { 天然水位资料法、年保证率法、最低年 } \\
\text { 平均水位法、生态水位法、湖泊形态分 } \\
\text { 析法、最小空间需求法 }\end{array}$ & 最低生态水位 $22.62 \mathrm{~m}$ \\
\hline Zhang 等 ${ }^{[42]}$ & 城陵矶站 & $2005-2012$ 年 & 圥余分析法、响应面分析法 & $\begin{array}{l}\text { 枯期最低保护水位 } 20.58 \text { } \\
21.46 \mathrm{~m}\end{array}$ \\
\hline 梁婕等 ${ }^{[31]}$ & 城陵矶站 & $1952-2006$ 年 & $\begin{array}{l}\text { 突变前历年月均水位序列拟合最合适 } \\
\text { 的概率分布函数, 每月概率最高的水位 } \\
\text { 为生态水位 }\end{array}$ & $\begin{array}{l}1-12 \text { 月月平均水位: } 17.10 \text { 、 } \\
17.38 、 17.62 、 20.65 、 23.82 \text { 、 } \\
25.29 、 27.29 、 26.55 、 26.49 \text { 、 } \\
24.18 、 21.82 、 18.82 \mathrm{~m} \text {; 年平均 } \\
\text { 水位 } 22.26 \mathrm{~m}\end{array}$ \\
\hline 本文 & 城陵矶站 & 1953-2018 年 & IHA 及 RVA & 见 3.3 节 \\
\hline
\end{tabular}

上述方法所计算的结果均为较为单一的水位指标, 本文则从整体考虑生态系统的健康发展研究东洞庭 湖的适宜生态水位，计算成果包括 12 个月月平均水位、最高水位及其出现时间、最低水位及其出现时间、高 低水位发生次数、高低水位平均持续时间、涨落水次数、涨落水速率等共 24 个指标作为适宜生态水位计算 指标体系, 更为全面的约束生态系统的健康发展, 且每个指标给出了相应的阈值为适宜生态水位指标的范 
围,更具可操作性.

\section{5 结论}

本文基于城陵矶站 1953-2018 年的逐日水位资料,采用滑动 $t$ 检验法对年平均水位序列进行突变检 验. 将维持河流湖泊生态系统健康发展的水位阈值作为适宜生态水位, 分析城陵矶水位突变之前的变化规 律, 并借鉴 IHA 指标和 RVA 法提出一种包括逐月生态水位阈值和年内水位波动范围在内的适宜生态水位 指标体系计算其适宜生态水位, 分析突变后的水位是否满足适宜生态水位需求, 得出主要结论如下:

1) 城陵矶站年均水位由于人类活动导致的最可能的突变点为 2004 年,即可认为三峡水库蓄水导致其 下游年均水位开始变化的时间为 2004 年.

2) 三峡水库蓄水前, 东洞庭湖适宜生态水位需求包括以下内容, 逐月水位: 17.07 18.34、17.15 18.89、 $17.65 \sim 22.23 、 20.25 \sim 22.15 、 22.85 \sim 24.9 、 24.31 \sim 26.44 、 26.88 \sim 29.16 、 25.79 \sim 28.32 、 25.12 \sim 27.56 、 23.59 \sim$ $25.88 、 20.65 \sim 22.81 、 18.58 \sim 19.88 \mathrm{~m}$; 年最低水位: $16.21 \sim 17.86 \mathrm{~m}$, 发生时间第 $16 \sim 51$ 天(年积日); 年最高水 位:28.54 31.48 m, 发生时间第 187 211 天(年积日); 高水位平均持续时间 32.62 81.32 d/次, 低水位平均 持续时间 $52.13 \sim 107.65 \mathrm{~d} /$ 次; 涨水次数 $21.9 \sim 26.45$ 次, 涨水速率 $0.17 \sim 0.21 \mathrm{~m} / \mathrm{d}$; 落水次数 $23.17 \sim 27.6$ 次, 落水速率 $0.12 \sim 0.14 \mathrm{~m} / \mathrm{d}$.

3) 三峡建库后城陵矶站大部分时间能满足建库前适宜生态水位需求, 但三峡消落期 $1 、 2$ 月月平均水位 比适宜生态水位需求高 $0.83 、 0.27 \mathrm{~m}$; 蓄水期 10 月月平均水位比适宜生态水位需求低 $0.83 \mathrm{~m}$; 多年平均最低 水位高出适宜生态水位需求 $0.39 \mathrm{~m}$, 发生时间先于适宜生态水位需求 6 天, 涨水次数高于阈值要求 4 次, 涨 水速率低于阈值要求 $0.01 \mathrm{~m} / \mathrm{d}$; 落水次数高于阈值要求 2 次. 由于三峡建库后城陵矶水位不满足适宜生态 水位需求的时间较少, 且三峡运行后, 其上游溪洛渡、向家坝等水库也相继投人运行, 因此可考虑通过三峡 及上游梯级水库群调度来解决东洞庭湖区生态水位需求问题.

\section{6 参考文献}

[ 1 ] Tan GM, Li B eds. River management. Beijing: China Water Power Press, 2008. [谈广鸣, 李奔. 河流管理学. 北京: 中国水利水电出版社, 2008. ]

[ 2 ] Ma RH, Yang GS, Duan HT et al. China's lakes at present: Number, area and spatial distribution. Science China: Earth Science, 2011, 41(3) : 394-401. DOI: 10.1007/s11430-010-4052-6. [马荣华, 杨桂山, 段洪涛等. 中国湖泊的数量、 面积与空间分布. 中国科学:地球科学, 2011, 41(3) : 394-401.]

[ 3 ] Hu JJ, Zhang Y, Li P. Analysis of the variation of water area in Dongting Lake based on MODIS data. Journal of Heilongjiang Institute of Technology, 2017, (2) : 25-29. [ 胡金金, 张艳, 李鹏. 基于 MODIS 数据的洞庭湖水体面积变 化分析. 黑龙江工程学院学报, 2017, (2): 25-29.]

[ 4 ] Meng X, Liao XH, Li XC. Study on characteristics of water level variation in Dongting Lake and its influences. Yangtze River, 2014, (13) : 17-21. [孟熊, 廖小红, 黎昔春. 洞庭湖水位变化特性及影响研究. 人民长江, 2014, (13): 17-21.]

[ 5 ] Zhang GG, Wang CM, Tian Q. Changes of water quality in Lake Dongting before and after Three Gorges Project operation. J Lake Sci, 2016, 28 (4) : 734-742. DOI: 10.18307/2016.0406. [ 张光贵, 王丑明, 田琪. 三峡工程运行前后洞庭湖 水质变化分析. 湖泊科学, 2016, 28(4): 734-742.]

[ 6 ] Wang Q, Ou FP, Zhang L et al. Changes of water environment in Dongting Lake and its impact analysis after the Three Gorges Project operation. Resources and Environment in the Yangtze Basin, 2015, 24(11): 1843-1849. [王琦, 欧伏平, 张雷等. 三峡工程运行后洞庭湖水环境变化及影响分析. 长江流域资源与环境, 2015, 24(11) : 1843-1849.]

[ 7 ] Keddy PA, Remicek AA. Great lakes vegetation dynamics: The role fluctuating water levels and buried seeds. Journal of Great Lakes Research, 1986, 12(1) : 25-36.

[ 8 ] Peng YR. Study on ecological water level and water regime of the Dongting Lake under volume changes [Dissertation]. Changsha: Changsha University, 2013. [彭也茹. 水量变化下洞庭湖生态水位及水情研究 [ 学位论文]. 长沙: 湖南 大学, 2013.]

[ 9 ] Liu Y, Guo HC, Zhou F et al. Role of water level fluctuation on aquatic vegetation in lakes. Acta Ecologica Sinica, 2006, 
26(9) : 3117-3126. [刘永, 郭怀成, 周丰等. 湖泊水位变动对水生植被的影响机理及其调控方法. 生态学报, 2005, 26(9) : 3117-3126.]

[10] Wang JN, Li C, Liao WG. Impacts of the regulation of Three Gorges-Gezhouba cascaded reservoirs on downstream eco-hydrology. Journal of Hydroelectric Engineering, 2011, 30(2) : 84-95. [王俊娜, 李独, 廖文根. 三峡-葛洲坝梯级水库调 度对坝下河流的生态水文影响. 水力发电学报, 2011, 30(2): 84-95.]

[11] Jia YF. Impact of water level fluctuation on Siberian Crane and other wintering waterbirds in Poyang Lake[Dissertation]. Beijing: Beijing Forestry University, 2013. [贾亦飞. 水位波动对鄱阳湖越冬白鹤及其他水鸟的影响研究 [ 学位论 文]. 北京: 北京林业大学, 2013.]

[12] Gleick PH. Water in crisis: Paths to sustainable water use. Ecological Applications, 1998, 8(3) : 571-579. DOI: 10. $2307 / 2641249$.

[13] Song JX, Xu ZX, Liu CM et al. Ecological and environmental instream flow requirements for the Wei River-the largest tributary of the Yellow River. Hydrological Processes, 2007, 21: 1066-1073. DOI: 10.1002/hyp.6287.

[14] Cui BS, Zhao X, Yang ZF. Eco-hydrology-based calculation of the minimum ecological water requirement for lakes. Acta Ecologica Sinica, 2005, 25(7): 1788-1795. [崔保山, 赵翔, 杨志峰. 基于生态水文学原理的湖泊最小生态需水量 计算. 生态学报, 2005, 25(7): 1788-1795.]

[15] Shu C, Liu SX, Mo XG et al. Estimation of instream ecological flow based on RVA. Ecology and Environmental Sciences, 2010，19(5): 1151-1155. [ 舒畅, 刘苏峡, 莫兴国等. 基于变异性范围法(RVA) 的河流生态流量估算. 生态环境 学报, $2010,19(5): 1151-1155$.]

[16] Tharme RE. A global perspective on environmental flow assessment: Emerging trends in the development and application of environmental flow methodologies for rivers. River Research and applications, 2003, (19) : 397-441. DOI: 10.1002/ rra. 736 .

[17] Armentrout GW, Wilson JF. An assessment of low flows in streams in northeastern Wyoming. Water-Resources Investigations Report, 1987. DOI: 10.3133/wri854246.

[18] Matthews RC, Bao Y. The Texas method of preliminary instream flow assessment. Rivers, 1991, 2(4) : 295-310.

[19] Cui Y, Zhang Q, Chen XH et al. Advance in the theories and calculation methods of ecological water requirement. J Lake Sci, 2010, 22(4) : 465-480. DOI: 10.18307/2010.0401. [崔瑛, 张强, 陈晓宏等. 生态需水理论与方法研究进展. 湖泊科学, 2010, 22(4): 465-480.]

[20] Richter BD, Baumgartner JV, Braun PDP. A method for assessing hydrologic alteration within ecosystems. Conservation Biology, 1996, 10(4) : 1163-1174. DOI: 10.1046/j.1523-1739.1996.10041163.x.

[21] Ubertini L, Manciola P, Casadei S. Evaluation of the minimum instream flow of the Tiber River Basin. Environmental Monitoring and Assessment, 1996, 41(2) : 125-136. DOI: /10.1007/BF0039433.

[22] King JM, Tharme RE, De Villiers MS. Environmental flow assessments for rivers: manual for the building block methodology. Pretoria: Water Research Commission, 2000.

[23] Poff NL, Richter BD, Arthington AH et al. The ecological limits of hydrologic alteration (ELOHA) : A new framework for developing regional environmental flow standards. Freshwater Biology, 2010, 55(1) : 147-170. DOI: 10.1111/j.13652427.2009.02204.x.

[24] Baird AJ, Wilby RL. Eco-hydrology: Plants and water in terrestrial and aquatic environments. London and New York: Routledge, 1999.

[25] Xu ZX, Wang H, Tang KW et al. Minimum ecological water requirements for lakes taking in-sending out water. Resources Science, 2005, 27(3) : 140-144. [徐志侠, 王浩, 唐克旺等. 吞吐型湖泊最小生态需水研究. 资源科学, 2005,27 (3) : 140-144.]

[26] Li XH, Song YD, Li YT et al. Calculation methods of lowest ecological water level of lake. Arid Land Geography, 2007, 30(4) : 526-530. [李新虎, 宋郁东, 李岳坦等. 湖泊最低生态水位计算方法研究. 干旱区地理, 2007, 30(4): 526-530.]

[27] Xu ZX, Chen MJ, Dong ZC. Researches on the calculation methods of the lowest ecological water level of lake. Acta Ecologica Sinica, 2004, 24(10): 2324-2328. [徐志侠, 陈敏建, 董增川. 湖泊最低生态水位计算方法. 生态学报, 2004, 24(10): 2324-2328.]

[28] Zhao X, Cui BS, Yang ZF. A study of the lowest ecological water level of Baiyangdian Lake. Acta Ecologica Since, 2004, 
25(5) : 1033-1040. [赵翔, 崔保山, 杨志峰. 白洋淀最低生态水位研究. 生态学报, 2004, 25(5) : 1033-1040.]

[29] Cheng JX, Xu LG, Wu R et al. Study on the lowest ecological water level of East Dongting Lake. Jiangxi Science, 2015, (6) : 932-937. [程俊翔, 徐力刚, 吴睿等. 东洞庭湖最低生态水位研究. 江西科学, 2015，(6) : 932-937.]

[30] Xu ZX. Research on ecological water requirements for rivers and lakes [Dissertation]. Nanjing: Hohai University, 2005. [徐志侠. 河道与湖泊生态需水研究 [ 学位论文]. 南京 : 河海大学, 2005.]

[31] Gan F, Tang L, Guo HC et al. New method and application of estimating ecological water level of the Lake Poyang. J Lake Sci, 2015, 27 (5) : 783-790. DOI: 10.18307/2015.0504. [涂峰, 唐琳, 郭怀成等. 湖泊生态水位计算新方法与应 用. 湖泊科学, $2015,27(5): 783-790$.

[32] Chen Y, Guan YQ, Miao JZ et al. Determination of the ecological water-level and assuring degree in the Lake Gaoyou, northern Jiangsu with long-term hydrological alteration. J Lake Sci, 2017, 29(2) : 398-408. DOI: 10.18307/2017.0216. [陈玥, 管仪庆, 苗建中等. 基于长期水文变化的苏北高邮湖生态水位及保障程度. 湖泊科学, 2017, 29(2): 398-408. ]

[33] Liang J, Peng YR, Guo SL et al. Determination of ecological water-level in the eastern Lake Dongting with hydrological alterations. J Lake Sci, 2013, 25(3) : 330-334. DOI: 10.18307/2013.0303. [梁婕, 彭耶茹, 郭生练等. 基于水文变异 的东洞庭湖湿地生态水位研究. 湖泊科学, 2013, 25(3) : 330-334.

[34] Kong HM. Theory and indication system of forest ecosystem health assessment [Dissertation]. Beijing: University of Chinese Academy of Sciences, 2002. [孔红梅. 森林生态系统健康理论与评价指标体系研究 [学位论文]. 北京: 中 国科学院研究生院, 2002.]

[35 ] Richter BD, Baumgartner JV, Braun DP et al. A spatial assessment of hydrologic alteration within a river network. Regulated Rivers Research and Management, 1998, 14(4) : 329-340. DOI: 10.1002/(SICI) 1099-1646(199807/08) 14:4< 329: AID-RRR505>3.0.CO;2-E.

[36] Richter BD, Baumgartner JV, Wigington R et al. How much water does a river need. Freshwater Biology, 1997, 37( 1): 231-249. DOI: 10.1046/j.1365-2427.1997.00153.x.

[37] Li XP, Huang GR, Jiang T. Evaluating alterations of runoff after Fenshuba reservoir Construction based on RVA method. Water Resources and Power, 2009, (3) : 18-21. [李兴拼, 黄国如, 江涛. RVA 法评估枫树坝水库对径流的影响. 水 电能源科学, 2009, (3) : 18-21.]

[38] Yang T, Zhang Q, Chen YD et al. A spatial assessment of hydrologic alteration caused by dam construction in the middle and lower Yellow River, China. Hydrological Processes, 2010, 22(18) : 3829-3843. DOI: 10.1002/hyp.6993.

[39] Xue NQ, Zhang H, Yang CB et al. Quantitative assessment of hydrological alteration caused by irrigation projects in the Tarim River basin, China. Scientific Reports, 2017, 7(1) : 4291. DOI: 10.1038/s41598-017-04583-y.

[40] Yuan YJ, Zhang C, Zeng GM et al. Quantitative assessment of the contribution of climate variability and human activity to streamflow alteration in Dongting Lake, China. Hydrological Processes, 2016, (30): 1929-1939. DOI: 10. 1002/ hyp. 10768.

[41] Liao WT, Deng HB, Li RN et al. Effects of dams on runoff in the lower reaches: A case study of the Gezhouba hydro-project and the Three Gorges Project. Acta Ecologica Sinica, 2018, 38(5) : 1750-1757. DOI: 10.5846/stxb201704070596. [廖文婷, 邓红兵, 李若男等. 水利工程对坝下径流的影响一以葛洲坝、三峡水利枢纽为例. 生态学报, 2018, 38 (5) : 1750-1757.]

[42] Yang YX, Du YC, Zhang JF et al. Determination of lowest ecological water level in Dongting Lake area. Water Resources Protection, 2019, (3) : 89-94. [杨毓金金, 杜春艳, 张金帆等. 洞庭湖湖区最低生态水位的确定. 水资源保护, 2019, (3) : 89-94.]

[43] Zhang C, Yuan YJ, Zeng GM et al. Influence of hydrological regime and climatic factor on waterbird abundance in Dongting Lake Wetland, China: Implications for biological conservation. Ecological Engineering, 2016, 90: 473-481. DOI: 10.1016/j.ecoleng.2016.01.076. 